\author{
Fotografía aérea con tecnología drone. \\ Tipología y aplicaciones
}

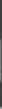

Manuel Blanco Pérez

Artigo recebido em: 01/07/2020

Artigo aprovado em: 22/07/2020

D0I 10.5433/1984-7939.2020v16n29p76 


\title{
Fotografía aérea con tecnología drone. Tipología y aplicaciones
}

\section{Aerial Photography with Drone Technology. Typology and Applications}

\author{
Manuel Blanco Pérez*
}

Resumen: La historia de la fotografia siempre ha estado unida a la de la aviación. Ambos inventos fueron creados en la misma época y ahora vuelven a converger gracias a los drones y las cámaras con que van equipados. En el último lustro la fotografia tomada desde los drones ha tenido aplicaciones en campos como la agricultura, la arquitectura, la publicidad, el periodismo o la seguridad. Esta investigación aborda su estudio ofreciendo como resultado una propuesta tipológica y de posibles aplicaciones.

Palabras clave: Drone. Fotografía aérea. Aplicaciones.

Abstract: The history of photography has always been linked to that of aviation. Both inventions were created at the same time and now they are converging again thanks to the drones and cameras they are equipped with. In the last five years, photography taken from the drones has had applications in fields such as agriculture, architecture, advertising, journalism and security. This research addresses their study, offering as a result a typological proposal and possible applications.

Keywords: Drone. Photography. Aerial. Applications.

* Profesor PDI (Personal Docente Investigador) de la Universidad de Sevilla. mblancoperez@us.es 


\section{Introducción. Fotografía y aviación: antecedentes}

Desde sus inicios el ser humano ha cartografiado su entorno en un intento de representar y representarse dentro de la realidad en que habita. Un mapeado vital que va mucho más allá del mero contorno físico pues, normalmente, los mapas van asociados al concepto de viaje. Algo que es, en sí mismo, una metáfora de la vida y del mundo: será el mito del "Monomuth" ("monomito") que formulara Joseph Campbell en 1949.

En ese representar su contorno, y como consecuencia de la Revolución Industrial, hubo dos inventos que cambiaron la historia del mundo, que nacen a la vez y se retroalimentan: la fotografía y la aviación. Será Gaspar Felix Tournachon, alias Nadar quien, como afirma Marie-Loup Sougez (2006), sea el primero en instalar una cámara fotográfica sobre un globo aerostático, en 1858, consiguiendo fotografiar los tejados de Petit-Becetre, no lejos de París.

Durante la Gran Guerra, la Segunda Guerra Mundial y la Guerra Fría y sus estertores, la sofisticación de ambos inventos creció separada la una de la otra. Fue en la guerra de Vietnam cuando el ejército de los Estados Unidos, para contrarrestar los tierra-aire de tecnología soviética, financió grandes investigaciones que fraguarían en los "lightning bugs":

"Esos «vehículos pilotados a distancia», explicaba entonces un oficial norteamericano, «evitan que las tripulaciones sean asesinadas o hechas prisioneras [...], gracias a ello, la supervivencia ya no es un factor determinante a tener en cuenta". (CHAMAYOU, 2016, p. 33). 
Uno de los fotógrafos que más partido ha sacado a la fotografía aérea en el pasado s. XX es, sin duda, el francés Yann Arthus-Bertrand:

Descubrió la fotografía tarde, a los 30 años, cuando estudiaba el comportamiento de una manada de leones en Kenia, suspendido en un globo de aire. A partir de ahí empezó una larga carrera de publicaciones en los medios más punteros del mundo, creó Altitude, la primera agencia de fotografía especializada en fotografía aérea, y arrancó el primero de sus grandes proyectos: la creación de un banco de imágenes de la Tierra vista desde arriba, patrocinado por la Unesco. Su libro La Tierra vista desde el cielo (1999) tuvo un éxito apabullante, con más de tres millones de copias vendidas. (EREÑAGA, 2015).

Esta tipología de fotografía, realizada con helicópteros comerciales, abre la posibilidad de ejecutarlas — prácticamente en situación idéntica- gracias a los drones actuales, con el consiguiente abaratamiento que suponen. De hecho, el propio Yann Arthus-Bretrand, en su último proyecto Mujeres (2020), ha desechado la posibilidad de usar helicópteros comerciales y, en cambio, ha firmado un mecenazgo con la empresa de drones DJI para realizar con sus aeronaves el conjunto del trabajo ${ }^{1}$. Ya no es Yann Arthus-Bretrand quien monta en un helicóptero - cámara en mano- sino, al contrario, quien desde tierra explica al piloto de drones el plano que desea ver sobre el monitor, y que luego disparará y editará él mismo.

1 Como parte de este mecenazgo comercial, la propia DJI ha creado una serie de vídeos en que el propio Yann Arthus-Bertrand explica la metodología de trabajo con el Drone DJI Inspired 2 para fotografía y tomas de vídeo en su última película. Se ha llamado Dji Masters, y el capítulo de Bretrand es recatable en: https://www.youtube.com/watch? $v=$ cqdsdJzoRyU 
Everett Rogers, en los albores de internet allá por 1985, propuso en su obra Diffusion of Innovations que, al menos, cinco factores influyen en la aceptación social de una nueva tecnología. Lo propuso cuando el debate informático en América comenzaba a ser asunto de estado por la irrupción en las casas del "personal computer" en los estertores de la Guerra Fría y justo cuando Apple despedía a Steve Jobs. No obstante, esos principios son plenamente aplicables a la tecnología drone 35 años más tarde. Rogers habla de que debe contener: "relative advantage" (ventaja frente a otros competidores); "compatibility" (compatibilidad, conectividad); "complexity" (la complejidad de resolucinones técnicas), "trialability" (betabilidad: necesidad de testeo para mejoras ulteriores); y, por último, “observability” (medición de carácter técnico de los resultados que aporta) (ROGERS, 1985, p. 232).

Tanto la industria armamentística como la del ocio, la ciencia aplicada, así como la ingeniería aeroespacial, promoverían la innovación de la fotografía y de la aviación por separado hasta que, hace apenas unos años, han vuelto a converger en una única herramienta que vuelve a cambiar el orden establecido: los drones. Aparatos no tripulados capaces de fotografiar y filmar en 360 grados en el aire con la misma calidad que en tierra. Neonatos, y cuyos usos aún no podemos vislumbrar en su totalidad. Pero, mas allá de ser un mero instrumento para hacer lo mismo que ya se podía hacer en fotografía de helicóptero, los drones obligan, especialmente desde la fotografía, a la reformulación de su propia ontología como medio pues, los drones, tienen infinidad de aplicaciones que no sería posible ejecutar desde un helicóptero comercial. 
Los drones han ido copando poco a poco ámbitos para los que nunca se diseñaron: empresas de reparto de mercancía -como Amazon- ya están ensayando prescindir de la mano de obra humana en su rutina laboral. En el campo de la comunicación, no obstante, el nacimiento de los drones no ha podido ser acogido con más entusiasmo. (BLANCO PÉREZ, 2020, p. 21).

Algunos de estos usos ya fueron avanzados por Torre Simón (2016) y actualizados por López Hidalgo (2016), si bien la literatura científica sobre el mundo de los drones y sus enormes posibilidades queda reducida a una dimensión estrictamente técnica (software, ingeniería y programación), más que a una reflexión pausada sobre sus aplicaciones en diversos campos. En este sentido, esta investigación tiene como objetivo abordar de forma cualitativa, mediante un estudio descriptivo, el uso y los otros usos de la fotografía aérea con tecnología drone con el fin de realizar una propuesta tipológica de sus posibles aplicaciones.

\section{Fotografía, arquitectura y arqueología: fotogrametría 3D}

La fotogrametría es "la técnica que tiene como objetivo estudiar y definir con precisión la forma, dimensiones y posición en el espacio de un objeto cualquiera utilizando esencialmente medidas hechas sobre una o varias fotografías" (BONNEVAL, 1972). Sus principales usos, hoy día, son para la arquitectura y la arqueología, en ambos casos realizando reconstrucciones vectoriales 3D a partir de fotografías. Es decir, el proceso arranca con la toma fotográfica de 
la zona, y se obtienen las coordenadas tridimensionales de dicha zona que, a su vez, dan lugar a distintos subproductos derivados de dichas fotografías: planos cartográficos, modelos digitales de elevaciones, ortofotos, y reconstrucciones de mapeado 3D vectorial. A nivel de software, cada vez están cada vez mas automatizados:

Reality Capture, 3DF Zephir o Pix4D, son otros softwares comerciales de fotogrametría, este último específico para drones. Todos ellos suelen permitir al usuario amplias opciones de configuración del modelado y una mayor intervención en cada uno de los pasos del proceso. Y ofrecen también una gran variedad de formatos de salida del modelo 3D. (CHARQUERO BALLESTER, 2016, p.142).

Este tipo de software es, por tanto, trascendental para las fotografías tomadas con drone pues supone la base para el mapeado vectorial ulterior, que se aplica en la actualidad tanto a reconstrucción virtual de edificios 3D como en reconstrucciones de antiguos emplazamientos y yacimientos en arqueología:

En definitiva, las principales ventajas de utilizar el drone y la fotogrametría en proyectos de investigación arqueológica es la calidad de la información obtenida en comparación con su bajo coste. La documentación es rápida y sencilla, solo limitada por los elementos naturales del entorno, los tendidos de alta tensión, las edificaciones o las zonas protegidas de vuelos aéreos. (RUIZ SABINA et al., 2015, p. 17)

En la ciudad de Sevilla, en 2009, la International of Virtual Archaeology organizó el encuentro Principles of Seville, en la Universidad, como continuidad a la carta de Londres (2006). Aunque 
en aquella época los drones estaban en una fase muy embrionaria (no había grandes compañías con monopolio de mercado, y proliferaban las placas low cost arduino ensambladas en pequeñas controladoras y dirigidas por RC), ya se pudo percibir que el mundo de la fotogrametría estaba siendo revolucionado con la proliferación de la fotografía digital y que, además, ésta debía reformular ciertos principios, se recoge en el manifiesto llamado "Los principios de Sevilla":

Se hace ineludible plantear un debate teórico de implicaciones practicas que permita a los gestores del patrimonio aprovechar lo mejor que las nuevas tecnologías pueden ofrecernos en esta materia minimizando sus aplicaciones mas controvertidas. En definitiva, se trata de establecer unos principios básicos que regulen las prácticas de esta pujante disciplina. (INTERNATIONAL FORUM OF VIRTUAL ARCHAEOLOGY, 2009, p. 2)

Pensemos que, para la obtención de una imagen 3D fiable, en fotogrametría, es fundamental el grado de detalle de los materiales (acabados de los edificios, o nivel de conservación de los muros en arqueología, por ejemplo), ello, necesariamente debe obtenerse, además, con una lente de focal medio (no valen aquí teleobjetivos ${ }^{2}$ ) $\mathrm{y}$, por tanto, esto sólo puede conseguirse con la cercanía entre la lente y lo fotografiado:

En este sentido, se puede concluir que, debido a la poca distancia de la construcción que proporcionan las imágenes tomadas por los drones, la información obtenida por este nuevo método es muy útil para los trabajos de restau-

2 Lo recomendado en estos casos suelen ser lentes luminosas (f1.4 / f2.8), con una distancia focal fija $(24 \mathrm{~mm}, 28 \mathrm{~mm}, 35 \mathrm{~mm})$ o variable de entre $17 \mathrm{~mm}$ y $35 \mathrm{~mm}$. 
ración arquitectónica. Además, las imágenes obtenidas, en muchos casos, pueden llegar a ser incluso más relevantes que la información que podría lograrse visitando los mismos elementos ${ }^{3}$. (MASCORT-ALBEA; RUIZ-JARAMILLO; ROMERO HERNÁNDEZ, 2014, p. 59).

El uso de una lente de teleobjetivo para la fotogrametría presenta dificultades añadidas como la pérdida de profundidad de campo derivada de la diafragmación, la aberración cromática o la distorsión visual. Ello sumado a lo que dificultaría los cálculos matemáticos el hecho de que las posiciones de disparo estuvieran separadas por grandes distancias entre sí. La única manera de realizarlo es con una lente muy cerca de su objetivo, luminosa y estable, y con formatos fotográficos que conserven toda la información tonal (RAW): y eso sólo lo puede proporcionar hoy día un drone. Además, la fotografía con drones aplicada a la arquitectura permite una trazabilidad evolutiva del estado de una obra o intervención para un mejor acceso al material gráfico:

Se ha visto ya cómo en esta fase técnica es posible y necesario pasar del simple archivado fotográfico de las etapas de cada intervención a la reproducción digital orientada a su difusión, primero entre profesionales $y$, en un sentido más amplio y necesariamente posterior, entre el público general. (RODRÍGUEZ SILGO, 2016, p. 74).

En lo que concierne a la fotografía de drones de arquitectura,

3 "In this sense, it can be concluded that due to the distance from building provided by images taken by the drones, the information obtained by this new method is useful for architectural restoration works. In addition, the images obtained, in many cases, may become even more relevant than the information that could be achieved by visiting the same elements". Traducción del autor. 
vinculándola a desastres naturales, el avance es tal que nos está llevando a reformular su propia ontología. Uno de los casos de estudios más paradigmáticos se dio con el tsunami japonés del 2011 que afectó, como sabe, a la central nuclear de Fukoshima. Recientes investigaciones utilizaron drones para fotografiar material radioactivo 137Cs esparcido por las inmediaciones. Dichas fotografías de drone fueron puestas en correlación a otras fotografías obtenidas de procesos topográficos para precisar el alcance de la contaminación:

Mostramos que la distribución de 137Cs en regiones con un diámetro de varias decenas a cien metros se puede representar con una resolución típica de 2-5 $\mathrm{m}$ dentro de una duración de vuelo de 10-20 min. Las imágenes aéreas de rayos gamma tomadas a 10 metros y 20 metros sobre el suelo son cualitativamente consistentes con un mapa de dosis reconstruido a partir de las mediciones realizadas en tierra utilizando un medidor topográfico ${ }^{4}$. (MOCHIZUKI et al., 2017).

Tradicionalmente, la fotografía de arquitectura solía realizarse con formato medio fotográfico, y lentes tilt-shift. En cambio, ahora, aunque buena parte de los fotógrafos siguen desarrollando su trabajo de esta manera, el hecho de poder obtener la toma en formato RAW, unido a cámaras de formato medio digitales y cuerpos DSLR Fx de gran cantidad de megapixels, hacen que haya proliferado el software capaz de emular el efecto óptico del basculamiento (tilt) y desplazamiento (shift) de la óptica descentrable. Algunas de las herramientas software más utilizadas para fotografía de arquitectura

4 "We show that the distribution of $137 \mathrm{Cs}$ in regions with a diameter of several tens to a hundred meters can be imaged with a typical resolution of $2-5 \mathrm{~m}$ within a 10-20 min flights duration. The aerial gamma-ray images taken $10 \mathrm{~m}$ and $20 \mathrm{~m}$ above the ground are qualitatively consistent with a dose map reconstructed from the ground-based measurements using a survey meter". Traducción del autor. 
son Autocad, 3D Studio Max, Cypecad, Arkö, Sketchup o su plugin V-Ray, además de la Creative Suite de Adobe (Photoshop, Illustrator. InDesing).

\section{Fotografía publicitaria}

La fotografía publicitaria es aquella que, cumpliendo cierta intencionalidad comunicativa estética, sin embargo, ha de tener una máxima: la creación de un concept de corte creativo que no está sujeto a otros códigos como el de veracidad o deontología de la comunicación:

"Cuando en publicidad, y sobre todo refiriéndose a las imágenes, se quiere establecer un catálogo de normas se corre el riesgo de quedarse con una casuística incompleta porque en publicidad la única norma que se cumple es la creatividad, la innovación". (SUSPERREGUI, 2005, p. 757).

Y es que, efectivamente, la fotografía publicitaria arrastra tras de sí una larga lista de soportes y códigos novedosos en su propia ontología, en ocasiones adoptados con la agilidad que demanda el mercado industrial:

Tan desorbitado ha sido el desarrollo que ha alcanzado la industria Fotopublicitaria en nuestros días que podríamos atrevemos a decir, sin riesgo a equivocarnos, que si bien el siglo XIX fue el siglo de la Fotografía de Prensa, el siglo XX pasa por ser la época de dominio de la Fotografía de Publicidad, como manifiestamente atestiguan la prensa ilustrada de nuestros días y, sobre todo, las nuevos soportes de la Publicidad Exterior. (CORONADO E HIJÓN, 2000, p. 308). 
Eso que Diego Coronado e Hijón (2000) llama "los nuevos soportes de la publicidad exterior" encajan de manera precisa con las innovaciones tecnológicas de nuestros días y, muy específicamente, lo que para el sector supone la fotografía a través de los drones.

En los albores de esta tecnología, allá por el año 2014 y, ante la laguna legal regulatoria de aquel entonces, se realizan en algunos países propuestas muy básicas consistente en colgar un cartel sobre un drone: esto hará la empresa Uber, en México DF, en el verano del 2016. Esta técnica muestra un "protolenguaje" muy embrionario publicitario al pasar un cartel tradicional, a un medio novedoso, pero posee serios inconvenientes: para que la lectura del cartel pueda realizarse, el drone no podrá tomar más altura de unos dos metros y, además, no podrá colocarse en lugares en donde la lectura del cartel que porta sea inviable (autovías, medianas de avenidas concurridas, etc.), es decir: más allá de lo novedoso del soporte el uso no puede ser mas tradicional. Sin embargo, algunos de los usos más creativos de esta tecnología, habían venido de empresas minoristas como la brasileña Colombo (Camisaria), que usó drones DJI Inspired, el 1 de noviembre del 2014, para elevar maniquíes que portaban jeans y llevaban sus camisas: estos cuerpos flotantes, en vez de cabeza, eran soportados por el propio drone. Eso dejó miles de fotografías en redes sociales de personas "flotando" en la Villa Olimpia, en el Business District de Sao Paulo, y ocasionó cierto revuelo mediático.

"Imagínenos esta escena: un ejecutivo está sentado en su escritorio y al mirar por la ventana descubre flotando un maniquí sin cabeza vestido con traje. Una vez que se da cuenta que no está soñando, ¿qué haría este ejecutivo? Como mínimo hemos despertado su curiosidad". (DRONE ..., 2016). 
Por tanto, la fotografía tomada por drone puede suponer un revulsivo en el sector siempre que no se limite a la mera extensión de lo que ya se hace en cartelería o diseño, al contrario, podrá tener impacto considerable si se es capaz de, cumpliendo el marco regulatorio, construir un discurso novedoso vinculado a la fotografía y la tecnología drone: un ejemplo de ello puede ser el espectáculo que el gobierno de Shanghái programó para la entrada del año 2020: un ejército de 2.000 drones controlados ejecutaron una coreografía de formas y colores en el cielo de la zona portuaria, en lo que en el periódico El País (2 de enero de 2020) convinieron en llamar la "sustitución de los fuegos artificiales" (LOS DRONES ..., 2020). Ello generó una ingente cantidad de fotografías, un gran material gráfico usado por sus ciudadanos en redes sociales a modo de felicitación del año nuevo, en desuso de las viejas postales de fuegos artificiales.

La tecnología drone, para los fotógrafos, ha supuesto un mundo revolucionario donde apenas estamos comenzando a vislumbrar las posibilidades. Del mismo modo que la invención de las lentes que propiciaron la aparición del microscopio o del telescopio doméstico, la tecnología drone nos permite ver el mundo, nuestro mundo, con otros ojos radicalmente distintos y eso, en el lenguaje publicitario, es siempre un eje creativo en sí mismo.

\section{Fotografía fotoperiodística}

El periodismo, también en su dimensión gráfica, es la única de las ramas fotográficas de imágenes obtenidas con drone que 
estarían sujetas a un código deontológico profesional:

[...] la tecnología es un medio que permite enlazar lo insospechable con lo imaginable, llegando a ser una tentación en la alteración de la "realidad", por lo que se deben crear y reglamentar códigos de ética que responsabilicen, por lo menos de manera moral, a quienes hagan un mal uso de estas herramientas. (CASTELLANOS, 2004, p. 100).

Sin menoscabo de lo dicho, y como quiera que el fotoperiodismo es una rama del periodismo, sí que es preciso explicar el impacto que está ya teniendo en el oficio periodístico. Si bien el marco regulatorio (del 2017), que veremos más adelante, ha supuesto una ralentización de su implantación en los diferentes formatos periodísticos, y como dice Antonio López Hidalgo:

El uso de drones en el periodismo acaba de iniciar su vuelo y el futuro, a vista de pájaro, parece prometedor. El periodismo dron da sus primeros aletazos pero las imágenes que muestra y mostrará dibujan un paisaje hasta ahora nuevo y desconocido. Asimismo, se muestra como la herramienta más útil a la hora de captar imágenes de ciudades devastadas por la guerra, de desastres naturales, de conflictos bélicos, atentados terroristas, de eventos deportivos como los estadios de fútbol. (LÓPEZ HIDALGO, 2016, p. 249)

Entre 2015 y 2020 la tecnología drone ha evolucionado tanto que puede decirse, sin temor, que estamos en otro paradigma de creación de material fotográfico. Si en 2017 Fernández Barrero vislumbraba:

"Las pequeñas cámaras (GoPros) instaladas en quadcópteros, por ejemplo, no ofrecen la calidad adecuada para la cinematografía 
aérea. Según estos expertos, el uso de drones con cámaras para uso profesional se encuentra en un nivel emergente". (FERNÁNDEZ BARRERO, 2018, p. 40).

Es justo reseñar que la tecnología drone actual, apenas tres años transcurridos de esa cita, permite obtener imágenes de la misma calidad que cualquier cámara fotográfica. Y lo es por dos motivos, en primer lugar, porque físicamente hay modelos (DJI Inspired 2) capaces de levantar una cámara de formato medio (una Hasselblad H6D-400c, por ejemplo) con soltura durante casi media hora, con una altura de hasta $7 \mathrm{~km}$. y un radio de alcance de hasta $10 \mathrm{kms}$. Y segundo porque, incluso con drones de gama media, pueden obtenerse fotografías con ópticas Hasselblad de apertura f2.8 y en formato RAW (DNG) con lo que, a efectos prácticos, cualquier rango fotográfico profesional de calidad que sea obtenible sobre un trípode, lo es ya hoy, también, sobre un drone. De ahí que en las Facultades de periodismo estén proliferando sus estudios:

Matt Waite creó el Laboratorio de Periodismo Dron de la Universidad de Nebrasca-Licoln, en Estados Unidos, con el objeto de explorar cómo los drones podían utilizarse para informar. Las barreras legales siguen bloqueando las expectativas de este laboratorio y también de otros nacidos con posterioridad. Pero también lo hacen aspectos como la seguridad, la privacidad, la ética y el derecho a la información en el periodismo dron. (LÓPEZ HIDALGO, 2016, p.251). 


\section{Fotografía de drones: fiscalidad y seguridad}

La fotografía de drones viene utilizándose en los últimos años, además, para aligerar los trámites desde el Estado en lo que tiene que ver con fiscalidad y pago de tributos por nuevas construcciones y/o ampliaciones de las ya existentes. $\mathrm{Si}$, tradicionalmente, para fiscalizar que una ejecución de obra se había hecho de forma respetuosa con el preceptivo permiso de obra, era necesaria una orden judicial para la entrada en la vivienda o propiedad por parte de los técnicos de la Administración pública, con el consiguiente laberinto burocrático que eso conllevaba, desde la irrupción de la tecnología drone, la constatación se hace por fotografía de drone, especialmente en fincas $\mathrm{y}$ predios edificados sobre terrenos no urbanos y que, por tanto, no contraviene la actual legislación drone para sobrevolar zonas pobladas. El entonces Ministro de Hacienda, Cristóbal Montoro, incluyó esta tecnología en su Ministerio:

La decisión de utilizar nueva tecnología como estos objetos voladores para luchar contra el fraude la tomó en 2013 el equipo de Cristóbal Montoro, bajo el Gobierno del PP. Desde entonces se han encontrado a través de fotos aéreas más de tres millones de inmuebles con construcciones que no tenían los permisos necesarios de los casi 77 millones de propiedades inspeccionadas hasta la fecha, según los datos recabados en la Dirección General del Catastro. (MARTÍNEZ, 2019).

Además, al serunaherramienta vehiculada al propio Ministerio de Hacienda, y como quiera que dicho Ministerio tiene potestad para la aplicación de carga impositiva y sanciones administrativas que 
contravengan lo establecido en sus disposiciones, esta fotografía de drone tendrá, por sí misma, estatus de prueba legal de infracción en caso de reclamación del afectado ante los tribunales de todo orden.

Igualmente, el Estado, para el fortalecimiento de su pulmón recaudador, ha recurrido a la tecnología de las fotografías de drone en el caso de las infracciones de tráfico y la obtención, así, de fotografías aéreas fijas del vehículo sancionado junto a las coordenadas de velocidad y localización origen de la sanción:

La DGT también ha comenzado a emplear drones para detectar infracciones de tráfico. Desde hace años ya opera desde el aire el sistema de control de tráfico Pegasus, que se despliega en helicópteros. Pero el coste de este sistema es muy superior al de una flota de drones. La DGT ya tiene 11 en funcionamiento y se ha adjudicado la compra de otros 27. Estos dispositivos, que comenzaron a funcionar en la operación salida del 1 de agosto, tienen dos horas de autonomía y pueden elevarse a 120 metros. Además de infracciones, sus cámaras detectarán situaciones de peligro o accidentes que requieran de apoyo logístico. (PECO, 2020).

Con respecto al uso de la fotografía drone para la seguridad, pese a su novedad posee cierto recorrido. Ya en el año 2015, la empresa de seguridad privada Prosegur fue la primera en obtener el reconocimiento del Ministerio de Fomento para operar con drones, "la licencia de la AESA le permitirá ofrecer servicios relacionados con la seguridad y vigilancia de instalaciones sensibles o zonas de difícil acceso como centrales energéticas o líneas de alta tensión" (PENALVA, 2015). Y es que, además de realizar labores de fotovigilancia a través de drones, también la industria privada 
ha adelantado mucho en el desarrollo del software, con algunas aplicaciones que abren el campo a otros usos, por ejemplo la capacidad de, a partir de una fotografía de drone, cribarla con un software que nos permita sabes cuántos manifestantes hay en dicha fotografía:

Podemos medir con exactitud la superficie de plazas y calles. Disponemos de mejores métodos para obtener fotografías de la multitud gracias a los drones y helicópteros policiales. Pero una vez que se tienen las fotos hace falta contar, bien manualmente, bien con un software adecuado capaz de analizar las fotos con precisión. (PÉREZ CASTELLS, 2019)

Por último, y a modo de conclusión de este epígrafe, es justo reseñar que también el ingente negocio de la telebasura y los paparazzi se apuntaron a la fotografía de drone como una oportunidad de obtener las llamadas "exclusivas". Algo que tenía y tiene implicaciones éticas, profesionales y, desde luego, legales, hablamos de:

[...] aparatos sobrevolando las residencias de las "celebrities", escenas que podrían dar mucho juego para las agencias de prensa y los medios interesados, pero que a la vez puede constituir una invasión de privacidad más allá de lo que hasta ahora han venido protagonizando los fotógrafos sensacionalistas a diario. (SCARPELLINI, 2014)

\section{Fotografía y agricultura}

Los drones, además de como sustitutos de las tradicionales 
fumigaciones (uso que, en principio, se aleja del medio fotográfico que investigamos), ha tenido en fechas recientes un hallazgo en lo concerniente a la monitorización de cultivos a partir de una toma fotográfica aérea.

Al principio se usaban aquellas imágenes que no tenían un costo tan elevado (Landsat 7 o Landsat 5), la información relevada era muy útil, pero la captura de imágenes se hacía cada 8 días dado que el satélite demoraba esa cantidad de días para regresar al mismo punto y muchas veces el factor climático no permitía buenas tomas para definir manejos en los cultivos. (INSTITUTO NACIONAL DE TECNOLOGÍA AGROPECUARIA; ESTACIÓN EXPERIMENTAL AGROPECUARIA MANFREDI, 2015).

Para aminorar esos 8 días, se debía contratar a una avioneta o helicóptero más un fotógrafo especializado. Ello reducía el tiempo de espera a la mitad, pero aún así, es demasiada demora cuando se trata de control de plantaciones tras desastres naturales, o en situaciones de sequías, por ejemplo. Por ello, el drone permite realizar un seguimiento de los cultivos instantáneo frente a un ataque de plagas y enfermedades, monitorizar la fertilización e incluso una inspección ocular y reenvío del material fotográfico en situaciones en que es difícil caminar por los cultivos.

La ortofoto NDVI generada a partir de las fotografías de la cámara NGB permitió la selección de tres zonas para inspección en campo y evidenció que la respuesta espectral sí permite identificar problemas en el cultivo, en tanto tonalidades cafés y rojizas indican un índice NDVI bajo y se asocian a un suelo desnudo, problemas de crecimiento o presencia de plantas invasoras. [...] Con ellos, se pueden 
hacer análisis y censos puntuales de alta precisión, con fotografías de $5,0 \mathrm{~cm} /$ pix a $100,0 \mathrm{~m}$ lo que puede disminuir el tiempo y trabajo no solo en zonas de difícil acceso, sino también en grandes extensiones. (BERRIO, 2015, p. 38).

Desde la Unión Europea, en 2015 se impulsó un consorcio integrado por 15 organismos públicos y privados, entre ellos las universidades Politécnica de Madrid, el CSIC y la Universidad Complutense de Madrid, en el Proyecto RHEA, (acrónimo de Robots-fleets Highly Effective Agriculture ${ }^{5}$ ) y que consistió en una flota de máquinas robotizadas constituida por tres tractores autónomos y dos drones especialmente diseñados, tanto a nivel de software como de hardware, para procesar la información en tiempo real, primeramente se realizaba un mapeado fotográfico $\mathrm{y}$, tras eso, una unión de esas fotografías para aplicarle una cartografía previa:

La fusión de imágenes es el proceso de creación del mosaico que combina las fotografías individuales de cada parte del campo en una sola imagen. En este proceso cobran especial importancia la precisión GPS del posicionamiento del dron y los algoritmos de búsqueda de características coincidentes en los bordes de las imágenes. (BARREIRO; VALERO, 2014, p. 40)

\section{Fotografía y marco jurídico}

La legislación con respecto a los drones era inexistente en España y el conjunto de los países de la Unión Europa hasta el 30 de diciembre de 2017, lo cual provocó que en esos años iniciales

5 Rescatable de: http://www.rhea-project.eu 
(2012-2016) fuera relativamente frecuente ver aeronaves surcando ciudades y monumentos históricos. En cambio, la regulación legal del 2017 que se aprobó en España, se caracterizó por su carácter extraordinariamente restrictivo, tanto para profesionales como para aficionados. Ana María Nimo y Jorge Barreno (2015) afirman que, en la práctica, conllevó la prohibición de poder fotografiar o filmar en un centro urbano y municipios. No obstante, a día de hoy, hay países con legislación más permisiva (en cuanto a zonas de vuelo, horario, permisos y licencias oficiales), que han favorecido las perspectivas de negocio aplicando los drones y sus fotografías (también sus vídeos) a varias de las sectoriales que hemos tenido oportunidad de analizar en estas líneas.

De igual modo, el derecho a la privacidad que viola la fotografía drone con respecto a las "celebrities" sigue siendo un debate social, y la regulación legal tendrá que verse actualizada en un futuro por códigos aplicados, y compromisos éticos por parte de los pilotos, profesionales y aficionados, así como una adaptación del código deontológico de los medios a este particular.

\section{Conclusiones}

De todos los usos posibles de los drones, en este estudio nos hemos centrado exclusivamente en su dimensión fotográfica: aunque tanto o más importantes son y serán los usos de las aeronaves en sí (sociales, políticos, empresariales, científicos, transporte, etc.), es cierto que todas ellas parten, primeramente, de la fotografía como marco de aplicación a otras ramas ulteriores. En ese sentido, es 
extraordinariamente razonable un escenario en que la tecnología siga avanzando a velocidad de crucero, y, al mismo tiempo el aparato legislativo (que siempre suele ir muy por detrás de los usos de la tecnología de la sociedad), genere literatura jurídica para perfilar el uso de la fotografía de drones en su vínculo a la legalidad y fiscalidad.

También en la aplicación fotográfica a los cultivos se prevé que será tangencial la fotografía de drone como resultado de la crisis climática planetaria en que estamos inmersos, y la optimización de recursos derivada de ello. A nivel de aplicación arquitectónica y arqueológica, la mejora de tiempo de vuelo de las aeronaves, y el avance (en términos de flexibilidad de la aplicación de la legislación vigente) favorecerá nuevos y novedosos métodos de fotografía en construcción civil y, además, favorecerá su aplicación a otras sectoriales vinculándola al turismo, el ocio o la cultura.

En el futuro, asimismo, el periodismo irá poco a poco volviéndose más aéreo y obligará a grandes e interesantes reformulaciones de su ontología en tanto vehículo comunicativo vinculante a un código deontológico. En cambio, la fotografía publicitaria pensada para aplicación por drones, al ser medios sin ataduras éticas en la información, es presumible que buscará nuevos métodos novedosos de comunicación visual estética en toda clase de subsectoriales publicitarias y con todo tipo de target: también aquí el medio es el mensaje.

En definitiva, lejos de ser este un trabajo totalizador o finalizador, si que nos ofrece una suerte de foto fija, de estado de la cuestión, o de enumeración de usos y aplicaciones de una tecnología que, pese a su juventud, no deja de ser una de las que más rango de aplicaciones nos ofrecerá al conjunto de la sociedad 
en años venideros pues, la mayoría de usos de los drones, y muy especialmente en su dimensión fotográfica, no pueden ser indexadas a día de hoy, sencillamente porque no existen aún, y no estamos si quiera cerca de vislumbrar cuándo y cómo se aplicarán.

\section{Referencias}

ARTHUS-BERTRAND, Yann. La Tierra vista desde el cielo. Madrid: Lunwerg, 1999.

BARREIRO, Pilar; VALERO, Constantino. Drones en la agricultura. Dossier Tierras, Madrid, n. 220, p. 36-42, 2014.

BERRIO, Viviana. Uso de drones para el análisis de imágenes multiespectrales en agricultura de precisión. @Limentech: Ciencia y tecnología alimentaria, Pamplona, Colombia, v. 13, n. 1, p. 28-40, 2015.

BLANCO PÉREZ, Manuel. Manual de tecnología para la comunicación audiovisual: de la cámara al drone. Salamanca: Comunicación Social, 2020.

BONNEVAL, Henri. Photogrammétrie générale. Paris: Eyrolles, 1972.

CAMPBELL, Joseph. El héroe de las mil caras. México, DF: Fondo de Cultura Económica, 1949.

CHAMAYOU, Grégoire. Teoría del drone: nuevos paradigmas de los conflictos del s. XXI. Barcelona: NED, 2016.

CHARQUERO BALLESTER, Ana María. Práctica y usos de la fotogrametría digital en arqueología. DAMA, Alicante, Spain, n. 1, p. 139-157, 2016. 
CORONADO E HIJÓN, Diego. Arte, fotografía y publicidad. Laboratorio de Arte, Sevilla, España, n. 13, p. 301-320, 2000.

DRONE marketing: ¿la publicidad del futuro? Prnoticias, Madrid, 20 oct. 2016. Marketing. Disponible en: http://bit.ly/39EiDn8. Acceso en: 1 abr. 2020.

EREÑAGA, Amaia. Human: miserias y grandezas del ser humano, vistas desde el cielo. NAIZ:, Madrid, 27 set. 2015. Reportajes. Disponible en: https://bit.ly/3oXeAsn. Acceso en: 1 abr. 2020.

FERNÁNDEZ BARRERO, María Ángeles. Periodismo y drones. Retos y oportunidades del uso de drones para la narración informativa en España. Doxa Comunicación, Madrid, n. 26, p. 35-58, 2018.

INSTITUTO NACIONAL DE TECNOLOGÍA AGROPECUARIA; ESTACIÓN EXPERIMENTAL AGROPECUARIA MANFREDI. Agitotal, Buenos Aires, Argentina, 2015. Maquinaria. Agri de Precisión. Disponible en: https://bit.ly/2N2UVZV. Acceso en: 1 abr. 2020 .

\section{INTERNATIONAL FORUM OF VIRTUAL ARCHAEOLOGY.}

Principles of Seville. Los Principios de Sevilla. Principios Internacionales de la Arqueología Virtual, 1., 2009, Sevilla, España. Borrador final [...]. Sevilla: Universidad de Sevilla, 2009. Disponible en: https://bit.ly/3oXefG7. Acceso en: 1 abr. 2020.

LÓPEZ HIDALGO, Antonio. El periodismo que contará el futuro. Chasqui. Revista Latinoamericana de Comunicación, Quito, Ecuador, n. 131, p. 239-256, 2016.

LOS DRONES sustituyen a la pirotécnica en la fiesta de fin de año de Shanghái. El País, Madrid, 2 ene. 2020. China. Disponible en: http://bit.ly/3nQE3T6. Acceso en: 1 abr. 2020. 
MARTÍNEZ, Edurne: Drones para hallar piscinas y obras ilegales en mil municipios españoles. La Verdad, Madrid, 9 feb. 2019. Fiscalidad. Disponible en: https://bit.ly/35OY3PI. Acceso en: 1 abr. 2020 .

MASCORT-ALBEA, Emilio; RUIZ-JARAMILLO, Jonathan; ROMERO HERNÁNDEZ, Rocío. Analizando el patrimonio cultural a través de vuelos no tripulados: nuevas estrategias de investigación de espacios rurales y urbanos. VAR: Virtual Archaeology Review, Madrid, v. 5, n. 11, p. 56-64, 2014.

MOCHIZUKI, Saku; KATAOKA, Jun; TAGAWA, Leo; IWAMOTO, Yoko; OKOCHI, Hiroschi; KATSUMI, Naoya. First demonstration of aerial gamma-ray imaging using drone for prompt radiation survey in Fukushima. Journal of Instrumentation, Londres, UK, v. 12, p. 11014, Nov. 2017.

NIMO, Ana María; BARRENO, Jorge. Generación drone. EI Mundo, Madrid, 22 oct. 2015. Tecnología. Disponible en: https://bit. ly/2N2V5R1. Acceso en: 1 abr. 2020.

PECO, Ramón. Radares espía y drones indetectables. La Vanguardia, Madrid, 23 feb. 2020. Tecnología. Disponible en: http://bit. ly/3qoqziQ. Acceso en: 1 abr. 2020.

PENALVA, Javier. Este drone no es cualquiera: es vigilante de seguridad y tiene licencia para volar. Xataca, México, 6 nov. 2015. Disponible en: http://bit.ly/3itauWv.

PÉREZ CASTELLS, Javier. Contar y manifestar, todo es empezar. El Debate de Hoy, Madrid, 16 sep. 2019. Sociedad. Disponible en: http://bit.ly/3oVHiK9.

RODRÍGUEZ SILGO, Alba. Digitalización y virtualización del patrimonio cultural. Hacia un nuevo horizonte en la conservación-restauración. Telos: Revista de Pensamiento, Sociedad y, Madrid, 
v. 102, p. 67-76, 2016.

ROGERS, Everett. Diffusion of innovations. Londres: Macmillan Publishing, 1985.

RUIZ SABINA, Juan Ángel; GALLEGO VALLE, David; PEÑA RUIZ, Cristina; MOLERO GARCÍA, Jesús Manuel; GÓMEZ LAGUNA, Antonio. Fotogrametría aérea por drone en yacimientos con grandes estructuras. Propuesta metodológica y aplicación práctica en los castillos medievales del Campo de Montiel. VAR: Virtual Archaeology Review, Madrid, v. 6, n. 13, p. 5-19, 2015.

SCARPELLINI, Pablo. Drones paparazzi, la última invasión de la privacidad. EI Mundo, Madrid, 5 ago. 2014. Disponible en: https:// bit.ly/3bODVkn. Acceso en: 1 abr. 2020.

SOUGEZ, Marie-Loup. Historia de la fotografía. Madrid: Cátedra, 2006.

SUSPERREGUI, José Manuel. La tecnología de la fotografía aplicada a la imagen publicitaria: el ejemplo del automóvil. En: LÓPEZ ITA, Rafael; MARZAL FELICI, Javier y GÓMEZ TARÍN, Francisco Javier (ed.). El análisis de la imagen fotográfica. Castellón: Biblioteca de la Universidad Jaume I, 2005. p. 746-759.

TORRES SIMÓN, Francisco Javier. EI drone aplicado al sector audiovisual. Madrid: T\&F, 2016. 